\title{
Anti-wrinkle effect of fermented black ginseng on human fibroblasts
}

\author{
QUYNH LIEN PHAM ${ }^{*}$, HYUN-JUN JANG ${ }^{*}$ and KYU-BONG KIM \\ Department of Pharmacy, College of Pharmacy, Dankook University, \\ Cheonan, Chungnam 31116, Republic of Korea
}

Received May 18, 2016; Accepted January 10, 2017

DOI: $10.3892 /$ ijmm.2017.2858

\begin{abstract}
Fermented black ginseng (FBG) is processed by the repeated steaming and drying of fresh ginseng followed by fermentation with Saccharomyces cerevisiae. It is known to possess anti-oxidative effects. Skin wrinkle formation is associated with oxidative stress and inflammatory reactions. The aim of this study was to determine whether FBG possesses anti-wrinkle activity using human fibroblasts (HS68). According to the Korea Ministry of Food and Drug Safety (MFDS) guidelines for the evaluation of the efficacy of functional anti-wrinkle cosmetics, we attempted to elucidate the effects of FBG on type I procollagen, matrix metalloproteinase (MMP)-1, MMP-2, MMP-9 and tissue inhibitor of metalloproteinase-2 (TIMP-2). In addition, the eye irritation potential of FBG was examined using the EpiOcular-EIT kit. Our results revealed that FBG was not cytotoxic at concentrations $<10 \mu \mathrm{g} / \mathrm{ml}$. It was considered as safe for the eyes at concentrations of up to $100 \mu \mathrm{g} / \mathrm{ml}$. Treatment with FBG at concentrations from 0.3 to $10 \mu \mathrm{g} / \mathrm{ml}$ significantly $(\mathrm{P}<0.05)$ increased the type I procollagen expression levels from $117.61 \pm 1.51$ to $129.95 \pm 4.47 \%$ in the human fibroblasts. By contrast, FBG significantly $(\mathrm{P}<0.05)$ decreased the MMP-1 expression level from 18.41 \pm 4.95 to $27.41 \pm 3.96 \%$. FBG at $3 \mu \mathrm{g} / \mathrm{ml}$ also increased the expression of TIMP-2 up to $154.55 \%$. However, FBG at $10 \mu \mathrm{g} / \mathrm{ml}$ decreased the expression levels of MMP-2 and MMP-9 to 45.15 and $66.65 \%$, respectively. These results suggest that FBG has potential anti-wrinkle effects as a potential ingredient in cosmetics.
\end{abstract}

Correspondence to: Professor Kyu-Bong Kim, Department of Pharmacy, College of Pharmacy, Dankook University, 119 Dandae-ro, Chungnam 31116, Republic of Korea

E-mail: kyubong@dankook.ac.kr

*Contributed equally

Key words: anti-wrinkle effect, fermented black ginseng, type I procollagen, matrix metalloproteinase-1, matrix metalloproteinase-2, matrix metalloproteinase-9, tissue inhibitor of metalloproteinase-2

\section{Introduction}

Skin functions as a barrier to protect the internal organs from environmental toxins. Skin consists of the epidermis, dermis and subcutaneous tissue. The epidermis is the outermost layer composed mainly of keratinocytes that secrete keratin protein and lipids to form the extracellular matrix (ECM), melanocytes to produce pigment, and Langerhans cells to present antigen (1). The dermis is the layer of skin beneath the epidermis. It is composed of connective tissues to provide tensile force and elasticity to skin through the ECM composed of collagen fibrils, microfibrils and elastic fibers (2). The subcutaneous tissue below the dermis is composed of fibroblasts to produce ECM proteins, macrophages to eliminate pathogens and adipocytes to conserve body fat (3-8).

The aging of the skin is induced by complex processes, including intrinsic (e.g., genetic mutation, cellular metabolism and hormonal changes) and extrinsic factors [e.g., chemicals, toxins, pollutants and ultraviolet (UV) radiation] (5,9-11). Aging skin is mainly associated with the general atrophy of ECM components with a decrease in the number of fibroblasts, reduced levels of collagen and elastin, and the disorganization of collagen fibrils and elastin fibers (12-14). Alterations in the levels of collagen and elastin primarily cause clinical symptoms of aging skin, such as wrinkles, sagging and laxity (15). The degradation of collagen and elastin in aged or photodamaged (UV-irradiation) skin is associated with matrix metalloproteinases (MMPs) released from epidermal keratinocytes and dermal fibroblasts (10,14-17).

The root of the ginseng plant (Panax ginseng Meyer, Araliaceae) is traditionally used as an herbal medicine in East Asian countries, including Korea, Japan and China. It is known to possess the ability to enhance physical performance, as well as to exert neuroprotective effects, enhance sexual function, and to exert anti-cancer effects (18-22). In addition, the antioxidant and/or anti-inflammatory effects of ginseng are considered to be relevant to its anti-aging effects on skin $(23,24)$. Pharmacologically active components in ginseng include polysaccharides, polyacetylenes and gisenosides, with ginsenosides being considered as the most important component (25). To date, about 50 types of ginsenosides have been identified from the ginseng root. These natural ginsenosides from raw ginseng are converted to more stable, bioavailable and bioactive forms through the processes of drying and/or steaming (26). 
Raw ginseng is processed into white ginseng by a simple drying process or into red ginseng by steaming and drying processes to preserve or improve the efficacy (27). Black ginseng is made from raw ginseng by repetitive steaming and drying processes. After being subjected to steaming and drying processes ( 9 times), raw ginseng will become black ginseng (28). The fermentaion of black ginseng using Saccharomyces cerevisiae can produce more active gisenosides $(29,30)$. Fermented black ginseng (FBG) has different ratios of bioactive ingredients and contents of ginsenosides compared to white or red ginseng $(31,32)$. However, the effects of FBG on skin remain unclear. Thus, the aim of this study was to determine the in vitro toxicity and anti-aging effect of FBG as a cosmetic ingredient on skin to provide safety and efficacy data to support the use of FBG as a comsmetic ingredient.

\section{Materials and methods}

Reagents. FBG was obtained from (Ginseng By Pharm Co., Ltd., Wonju, Korea). Its detailed composition information has been previously described (26). All media required for cell growth, such as Dulbecco's modified Eagle's medium (DMEM) high glucose, fetal bovine serum (FBS), penicillin-streptomycin, and trypsin-EDTA (0.25\%) were purchased from (Gibco-BRL Inc., Franklin Lakes, NJ, USA). 3-[4,5-Dimethylthiazol-2-yl]-2,5-diphenyl-tetrazoliumbromide (MTT), retinoic acid, Dulbeco's phosphate-buffered saline (D-PBS) were purchased from (Sigma-Aldrich, St. Louis, MO, USA). Cell lysis buffer, phenylmethylsulfonyl fluoride (PMSF), antibodies against MMP-9 (sc-3852S), $\beta$-actin (sc-1616), horseradish peroxidase-conjugated anti-rabbit IgG (7074) and anti-mouse IgG (7076) were purchased from (Cell Signaling Technology, Inc., Danvers, MA, USA). Polyvinylidene fluoride (PVDF) and antibody against tissue inhibitor of metalloproteinase (TIMP)-2 (MAB 3310) were purchased from Millipore (Billerica, MA, USA). All other reagents were of the highest quality available.

Cell culture. Human skin fibroblasts (HS68) were obtained from the American Type Culture Collection (ATCC, Manassas, VA, USA). The cells were cultured in DMEM containing $10 \% \mathrm{FBS}$ and $1 \%$ of penicillin-streptomycin at $37^{\circ} \mathrm{C}$ in a humidified atmosphere containing $5 \% \mathrm{CO}_{2}$.

Cell viability assay. The HS68 human fibroblasts were seeded onto 96-well plates at a density of $5 \times 10^{4}$ cells/well and incubated for $48 \mathrm{~h}$, as previously described (10). After $48 \mathrm{~h}$ of incubation, various concentrations of FBG $(10,25,50,100$, and $200 \mu \mathrm{g} / \mathrm{ml}$ in fresh medium) or distilled water (DW; control) were used to treat the cells. The cells were further cultured for $48 \mathrm{~h}$. Subsequently, $200 \mu \mathrm{l}$ of MTT $(0.5 \mathrm{mg} / \mathrm{ml}$ MTT in fresh medium) was added to each well followed by incubation at $37^{\circ} \mathrm{C}$ for $3 \mathrm{~h}$. The MTT medium was removed by aspiration and $200 \mu \mathrm{l}$ of dimethyl sulfoxide was added to each well. After reacting for $10 \mathrm{~min}$ at room temperature, formazan production was detected by measuring the optical density at $570 \mathrm{~nm}$ on a PowerWave XS microplate reader (BioTek Instruments, Inc., Winooski, VT, USA). Data were then expressed as a percentage of viable cells compared to viable cells in the DW-treated control.
Eye irritation test. The ocular irritation potential of FBG was examined using the EpiOcular Eye Irritation Test (OCL-200-EIT; MatTek Corp., Ashland, MA, USA). Following incubation at $37^{\circ} \mathrm{C}$ in $5 \% \mathrm{CO}_{2}$ overnight, OCL-200-EIT was pre-wet with $20 \mu \mathrm{l} \mathrm{Ca}^{++}$- and $\mathrm{Mg}^{++}$-free D-PBS (Sigma-Aldrich) for $30 \pm 2 \mathrm{~min}$. After pre-wetting, $50 \mu \mathrm{l}$ of FBG (10 and $100 \mu \mathrm{g} / \mathrm{ml}$ ) was topically applied to the pre-wet OCL-200-EIT and incubated for 30 $\pm 2 \mathrm{~min}$. Tissues included in OCL-200-EIT kit were then rinsed with $300 \mathrm{ml}$ D-PBS, post-soaked with $5 \mathrm{ml}$ fresh medium, and incubated for $2 \pm 0.4 \mathrm{~h}$ at $37^{\circ} \mathrm{C}$ with $5 \% \mathrm{CO}_{2}$. To measure cell viability, OCL-200-EIT was incubated with MTT solution $(1 \mathrm{~g} / \mathrm{ml}$ ) for $3 \mathrm{~h}$. After extracting isopropanol, the absorbance of formazan was measured at $570 \mathrm{~nm}$ on a PowerWave XS microplate reader (BioTek Instruments, Inc.). The mean value for each test substance was calculated from 2 wells. D-PBS was used as a control. Data were expressed as a percentage of the viability compared to that of the D-PBS-treated control.

Quantification of type I procollagen and MMP-1 levels. The levels of type I procollagen and MMP-1 in the human fibroblasts were quantified using the procollagen Type I C-peptide (PIP) EIA kit (Takara Bio, Inc., Otsu, Japan) and the Human MMP-1 ELISA kit (Young In Frontier, Seoul, Korea), respectively. The human fibroblasts were seeded at a density of $5 \times 10^{4}$ cells/well. After $48 \mathrm{~h}$, the cells were treated with DW (control), various concentrations of FBG $(0.3,1,3$ and $10 \mu \mathrm{g} / \mathrm{ml})$, or $0.03 \mu \mathrm{g} / \mathrm{ml}$ retinoic acid for $48 \mathrm{~h}$. The levels of type I procollagen and MMP-1 from the cultured media were measured using the Type I PIP EIA kit and Human MMP-1 ELISA kit according to the manufacturer's instructions. Data were expressed as the percentage of expression compared to that of the DW-treated control.

Quantification of MMP-2, MMP-9 and TIMP-2 levels. The expresssion levels of MMP-2, MMP-9 and TIMP-2 were measured by western blot analysis. The human fibroblasts were treated with DW (control), various concentrations of $\operatorname{FBG}(0.3,1,3$ and $10 \mu \mathrm{g} / \mathrm{ml})$, or $0.03 \mu \mathrm{g} / \mathrm{ml}$ retinoic acid for $48 \mathrm{~h}$. To extract total protein, the treated cells were incubated with cell lysis buffer (Cell Signaling Technology, Inc.) containing $1 \mathrm{mM}$ PMSF (Cell Signaling Technology, Inc.) for 5 min on ice. Following incubation, whole cell lysates were briefly sonicated and centrifuged at $12,000 \mathrm{rpm}$ for $20 \mathrm{~min}$ at $4^{\circ} \mathrm{C}$. The supernatant was stored at $-80^{\circ} \mathrm{C}$ until use. Before running on a gel, the protein concentration was determined by Bradford assay. Total protein $(25 \mu \mathrm{g})$ was separated by $10 \%$ SDS-PAGE and transferred onto PVDF membranes (Merck Millipore, Darmstadt, Germany) using a transfer apparatus (Bio-Rad Laboratories Inc., Hercules, CA, USA) according to the manufacturer's instructions. The membranes were incubated in blocking buffer (5\% w/v skim milk in TBST) for $3 \mathrm{~h}$. Primary antibody (1:1,000 for MMP-2, 1:500 for MMP-9, and 1:500 for TIMP-2) was incubated with the transferred membranes at $4^{\circ} \mathrm{C}$ overnight. After washing the membranes with TBST, the membranes were incubated with the secondary antibody (anti-rabbit for MMP-2 and MMP-9, anti-mouse IgG for TIMP-2 at 1:1,000 dilution) for $2 \mathrm{~h}$ at room temperature for MMP-2 or overnight at $4^{\circ} \mathrm{C}$ for MMP-9 and TIMP-2. After washing the membranes with TBST, protein signal was detected by horseradish peroxidase detection 

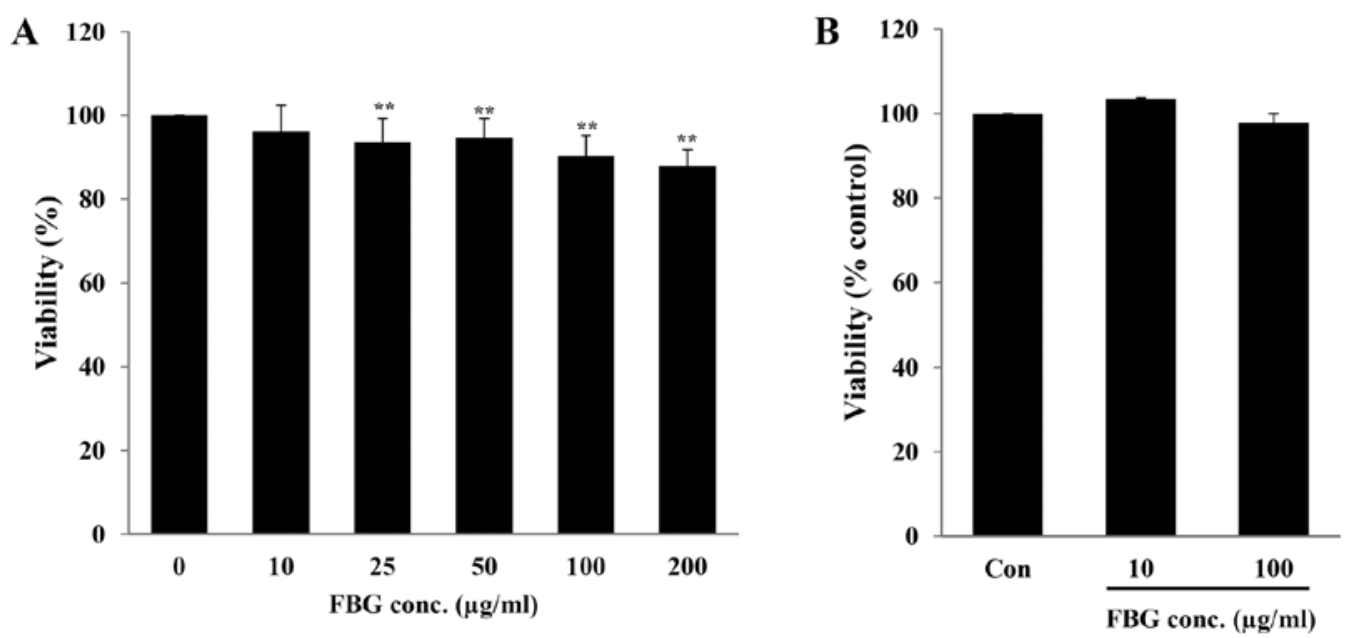

Figure 1. (A) Cytotoxicity of FBG. Human skin fibroblasts (HS68) were treated with DW or FBG (10-200 $\mu \mathrm{g} / \mathrm{ml})$ for $48 \mathrm{~h}$ and cell viability was determined by MTT assay. The data are the means \pm standard deviation values of 3 individual experiments. Each value was compared with the control using analysis of variance, followed by Bonferroni's test ( $\left.{ }^{* *} \mathrm{P}<0.01\right)$. (B) In vitro eye irritation was tested for FBG $(10 \mu \mathrm{g} / \mathrm{ml}$ and $100 \mu \mathrm{g} / \mathrm{ml}) \mathrm{using}$ the OCL-200-EIT. D-PBS was used as a control. FBG, fermented black ginseng; DW, distilled water; OCL-200-EIT, EpiOcular Eye Irritation Test; D-PBS, Dulbeco's phosphate-buffered saline.

system (Sigma-Aldrich). Data were expressed as a percentage of expression compared to that of the DW-treated control.

Statistical analysis. The means \pm standard deviations of the expression values were calculated using Microsoft Excel. The statistical significance $(\mathrm{P}<0.05$ or $\mathrm{P}<0.01)$ of apparent differences in protein expression among pre-dosing and treatments were assessed using analysis of variance followed by Bonferroni's test in Prism 5.01 (GraphPad Software, Inc., La Jolla, CA, USA).

\section{Results}

In vitro toxicity of $F B G$. The in vitro toxicity of $F B G$ on the skin and eyes, the major exposure routes of cosmetic ingredients, was evaluated using human skin fibroblasts (HS68) and the EpiOcular Eye Irritation test (OCL-200-EIT), respectively. When the HS68 cells were treated with $10,25,50,100$, and $200 \mu \mathrm{g} / \mathrm{ml} \mathrm{FBG}$ for $48 \mathrm{~h}$, cell viability was $96.17 \pm 6.36$, $93.68 \pm 5.64,94.64 \pm 4.66,90.31 \pm 4.97$ and $88.01 \pm 3.87 \%$, respectively. Only FBG at $10 \mu \mathrm{g} / \mathrm{ml}$ did not exhibit any significant difference in cell viability $(\mathrm{P}>0.05)$ compared to the control (without FBG treatment) (Fig. 1A). The EpiOcular-EIT results revealed that FBG at 10 and $100 \mu \mathrm{g} / \mathrm{ml}$ caused no potential eye irritation compared to the control (PBS treatment) (Fig. 1B). These results suggest that FBG at a concentration of $<10 \mu \mathrm{g} / \mathrm{ml}$ is not cytotoxic. In addition, FBG does not cause eye irritation at concentrations up to $100 \mu \mathrm{g} / \mathrm{ml}$.

Effect of FBG on the production of collagen. To examine the effect of FBG on collagen synthesis in skin, the fibroblasts were treated with FBG at non-cytotoxic concentrations. Our results revealed that $\mathrm{FBG}$ at $0.3,1,3$, and $10 \mu \mathrm{g} / \mathrm{ml}$ significantly $(\mathrm{P}<0.05)$ increased type I procollagen production to $117.61 \pm 1.51,122.62 \pm 2.69$, $128.07 \pm 5.76$, and $129.95 \pm 4.47 \%$, respectively, compared to the control (without FBG treatment). The positive control, retinoic acid at $0.03 \mu \mathrm{g} / \mathrm{ml}$, significantly increased $(\mathrm{P}<0.05)$ type I procollagen production to $120.88 \pm 5.82 \%$ compared to the control (without FBG treatment) (Fig. 2).

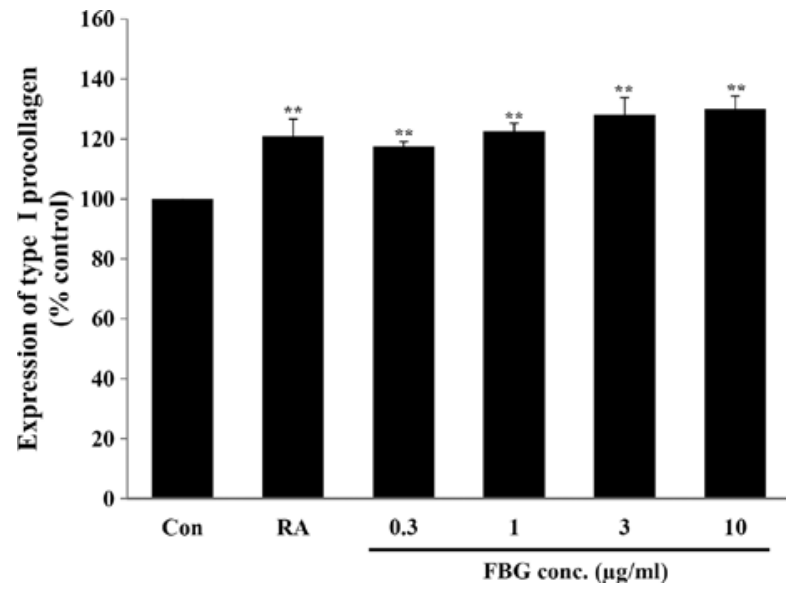

Figure 2. Effect of FBG on type I procollagen in human fibroblasts. Human fibroblasts were treated with DW (Con; control), RA $(0.03 \mu \mathrm{g} / \mathrm{ml}$ retinoic acid) or FBG $(10-200 \mu \mathrm{g} / \mathrm{ml})$ for $48 \mathrm{~h}$ and the expression of type I procollagen was measured using the Procollagen Type I C-peptide (PIP) EIA kit. The data are the means \pm standard deviation values of 3 individual experiments. Each value was compared with the control using analysis of variance, followed by Bonferroni's test $\left({ }^{* *} \mathrm{P}<0.01\right)$. FBG, fermented black ginseng; DW, distilled water.

Effect of FBG on MMPs. Subsequently, we analyzed the levels of MMPs associated with collagen degradation in FBG-treated HS68 fibroblasts. Our results revealed that FBG at concentrations of $0.3,1,3$ and $10 \mu \mathrm{g} / \mathrm{ml}$ significantly $(\mathrm{P}<0.05)$ decreased the MMP-1 levels by $18.41 \pm 4.96,19.35 \pm 6.39,21.53 \pm 7.81$ and $27.41 \pm 3.96 \%$, respectively compared to the levels of MMP- 1 in the control HS68 cells (without FBG treatment). The positive control, retinoic acid at $0.03 \mu \mathrm{g} / \mathrm{ml}$, also significantly $(\mathrm{P}<0.05)$ decreased the MMP-1 level by $37.78 \pm 7.71 \%$ compared to the level of MMP-1 in the control HS68 cells not treated with FBG (Fig. 3). In addition, in the cells treated with FBG at concentrations of $0.3,1,3$, and $10 \mu \mathrm{g} / \mathrm{ml}$, the expression levels of MMP-2 and MMP-9 were 76.32, 74.28, 52.71 and $45.15 \%$ and $106.66,100.00,90.53$ and $66.65 \%$ compared to those of the control, respectively. The positive control, retinoic acid at 


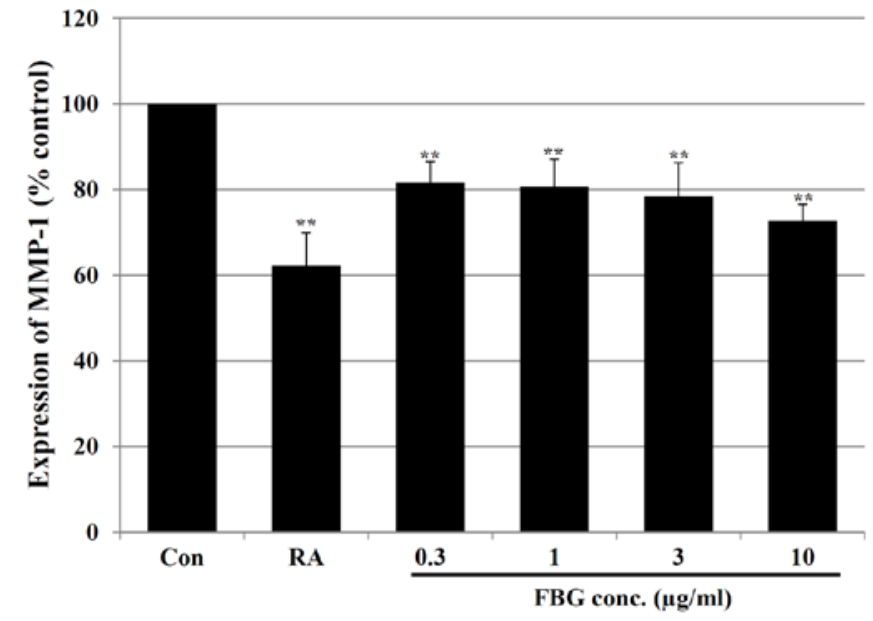

Figure 3. Effect of FBG on MMP-1 in human skin fibroblasts. Human skin fibroblasts were treated with DW (Con; control), RA $(0.03 \mu \mathrm{g} / \mathrm{ml}$ retinoic acid) or FBG $(0.3-10 \mu \mathrm{g} / \mathrm{ml})$ for $48 \mathrm{~h}$ and The expression of MMP-1 was measured using the human MMP-1 ELISA kit. The data are the means \pm standard deviation values of 3 individual experiments. Each value was compared with the control using analysis of variance, followed by Bonferroni's test $\left({ }^{* *} \mathrm{P}<0.01\right)$. FBG, fermented black ginseng; DW, distilled water; MMP-1, matrix metalloproteinase-1.

$0.03 \mu \mathrm{g} / \mathrm{ml}$, decreased the expression of MMP-2 and MMP-9 by $24.18 \%$ and $41.07 \%$ compared to control (Fig. 4). These results suggest that the levels of these MMPs were inhibited by FBG in a dose-dependent manner. The reduction in the levels of MMPs may be associated with the increased in type I collagen production caused by FBG treatment.

Effect of FBG on the expression of TIMP-2. TIMP-2 expression was examined in the FBG-treated HS68 cells. After the HS68 cells were treated with FBG at $0.3,1,3$ and $10 \mu \mathrm{g} / \mathrm{ml}$, the expression level of TIMP-2 was increased to $122.66,137.45,154.55$ and $126.76 \%$ compared to that of the untreated control. The positive control, retinoic acid at $0.03 \mu \mathrm{g} / \mathrm{ml}$, increased the level of TIPM-2 to $143.06 \%$ compared to that of the control (Fig. 5). These results suggest that FBG increases the levels of TIMP-2, thus causing the inhibition of MMPs.

\section{Discussion}

Ginsenosides are the major active components responsible for the pharmacological properties of ginseng (25). Ginsenosides can be grouped into protopanaxadiol, protopanaxatriol and oleanolic saponins based on their chemical structures (33). It has been previously reported that 20-O-b-d-glucopyranosyl-20(S)-protopanaxadiol (compound $\mathrm{K}$ ) of ginsenosides has anti-metastatic, anti-angiogenic and anti-allergic activities in vivo $(34,35)$. In particular, skin wrinkles and xerosis can be ameliorated by the topical application of compound $\mathrm{K}$ that induces hyaluronan synthase 2 in human keratinocytes and increases hyaluronan content in aged hairless mouse skin (36). In addition, skin wrinkles in humans can be improved by extracts from red ginseng roots with increased levels of type I procollagen (37). Collectively, these data suggest that the topical application of ginseng extracts can enhance its anti-wrinkle effects on human skin.
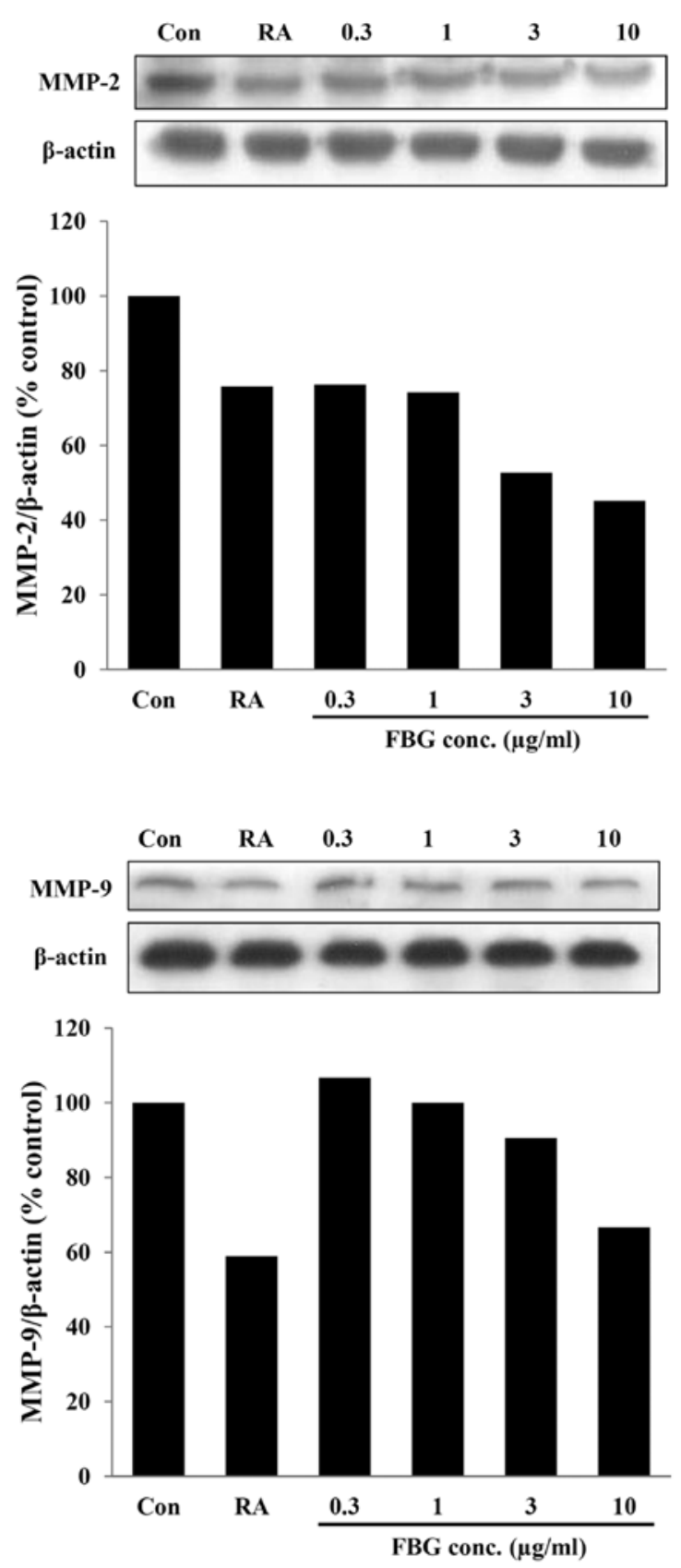

Figure 4. Effects of FBG on MMP-2 and MMP-9 in human skin fibroblasts. Human skin fibroblasts were treated with DW (Con; control), RA $(0.03 \mu \mathrm{g} / \mathrm{ml}$ retinoic acid) or FBG $(0.3-10 \mu \mathrm{g} / \mathrm{ml})$ for $48 \mathrm{~h}$ and the expression of MMP-2 and MMP-9 was measured by western blot analysis and normalized to the expression of $\beta$-actin. FBG, fermented black ginseng; DW, distilled water; MMP, matrix metalloproteinase.

FBG extracts display different compositions of ginsenosides by more complex processes, such as repetitive steaming and drying with fermentation using Saccharomyces cerevisiae compared to fresh, white, or red ginseng $(38,39)$. Such differences have been considered to be able to enhance their antioxidant and free radical scavenging activities (29,40-42). However, the anti-wrinkle effects of FBG extracts have not been studied on human skin. In the present study, FBG extracts significantly increased the expression of type I procollagen in human fibroblasts. This result indicates that FBG extracts have anti-wrinkle effects by increasing type I procollagen level in human skin. 

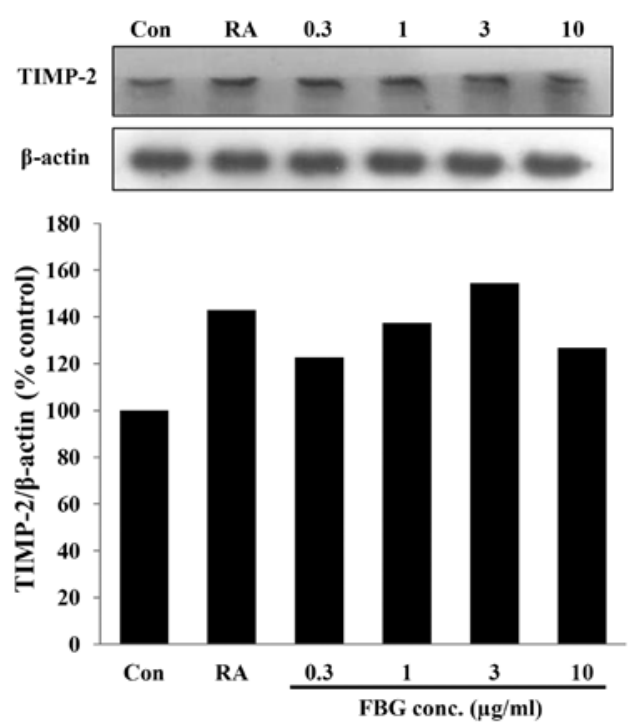

Figure 5. Effects of FBG on TIMP-2 in human skin fibroblasts. Human skin fibroblasts were treated with DW (Con; control), RA $(0.03 \mu \mathrm{g} / \mathrm{ml}$ retinoic acid) or FBG $(0.3-0 \mu \mathrm{g} / \mathrm{ml})$ for $48 \mathrm{~h}$ and the expression of TIMP-2 was measured by western blot analysis and normalized to the expression of $\beta$-actin. FBG, fermented black ginseng; DW, distilled water; TIMP-2, tissue inhibitors of metalloproteinase-2.

Type I collagen is the most abundant protein in skin connective tissue. It maintains skin structure with other types of collagen (III, V and VII), elastin, proteoglycans, fibronectin and other ECM proteins (43). Type I procollagen is synthesized in human dermal fibroblasts and secreted into the dermal extracellular space where it undergoes proteolytic processing. Finally, type I collagen forms collagen bundles (fibre bundles) that are responsible for the elasticity associated with other ECM proteins $(5,13)$. Fibrillar (types I and III) collagen can characteristically reduce chronologically aged and photo-damaged skin $(14,44,45)$. The degradation of type I collagen is closely associated with MMPs, a family of zinc-requiring endoprotease with the capacity to degrade all components of ECM (46). In particular, MMP-1 of the MMPs initiates the degradation of types I and III fibrillar collagens, while MMP-9 further degrades collagen fragments generated by collagenases (44). MMP-2 and MMP-9 together can cleave elastin, type IV collagen, and several other ECM molecules while MMP-2 can digest interstitial collagen types I, II, and III (47). It has been previously suggested that the function of MMP-1 is directly involved in the reduction of type I procollagen. MMP-2 and MMP-9 also regulate the expression of type I procollagen $(47,48)$. All known MMPs are inhibited by 4 homologous TIMPs (49). TIMP-2 of TIMPs inhibits ECM proteolysis in several tissues by directly inhibiting metalloproteinases, including MMP-2 (50). TIMP-2 is also known to be required for the activation of MMP-2 through association with MMP-14 (50,51). In this study, FBG extracts significantly inhibited the expression of MMP-1 in human fibroblasts. In addition, the expression levels of MMP-2 and MMP-9 were dose-dependently decreased by FBG. Moreover, the expresssion of TIMP-2 exhibited a generally increased tendency by FBG treatment. Collectively, these results suggest that the increase in the level of type I procollagen caused by FBG may be induced by the inhibition of MMP-1, MMP-2 and MMP-9.
The inhibition of these MMPs may correlated with the upregulation of TIMP-2 due to FBG treatment.

Retinoic acid can effectively attenuate the clinical symptoms of photodamaged skin. It can reverse the adverse consequences of chronological aged skin $(14,45,52)$. Treatment with retinoic acid can stimulate fibroblast proliferation, new collagen synthesis and the degradation of out-of-date or damaged collagen (53). The effects of retinoic acid are mainly associated with the inhibition of MMPs $(16,17)$. Additionally, retinoic acid results in the selective downregulation of MMP-9 and the simultaneous upregulation of TIMP-1 in human bronchoalveolar lavage cells (54). It can also reduce the expression of MMP-2 in human breast cancer cells, suggesting that the inhibition of MMP-2 may be due to upregulated TIMP-2 (55). In this study, we demonstrated that the treatment of human fibroblasts with retinoic acid exerted similar effects with FBG treament as regards the expression patterns of type I procollagen, MMP-1, MMP-2, MMP-9 and TIMP-2. These results suggest that $\mathrm{FBG}$ and retinoic acid may share similar mechanisms as regards their anti-wrikle effects on human skin.

In conclusion, our in vitro dermal study demonstrated that FBG treatment increased type I procollagen correlating with associated regulators. In addition, we assessed the non-toxic concentration of FBG through cosmetic exposure routes using human fibroblasts and ocular tissues. Conclusively, we demonstrated that FBG may be used as a safe cosmetic ingredient with anti-wrinkle effects.

\section{Acknowledgements}

This study was supported by the research fund of Dankook University in 2014. We would like to thank Professor Kyung-Min Lim (Ewha Womans University) for providing support to the current study.

\section{References}

1. Tobin DJ: Biochemistry of human skin - our brain on the outside. Chem Soc Rev 35: 52-67, 2006.

2. Farage MA, Miller KW, Elsner P and Maibach HI: Structural characteristics of the aging skin: A review. Cutan Ocul Toxicol 26: 343-357, 2007.

3. Breitkreutz D, Mirancea N and Nischt R: Basement membranes in skin: Unique matrix structures with diverse functions? Histochem Cell Biol 132: 1-10, 2009.

4. Kruglikov IL and Scherer PE: Dermal Adipocytes: From Irrelevance to Metabolic Targets? Trends Endocrinol Metab 27: 1-10, 2016.

5. Rittié L and Fisher GJ: UV-light-induced signal cascades and skin aging. Ageing Res Rev 1: 705-720, 2002.

6. Shiau CJ,Abi Daoud MS, Wong SM and Crawford RI: Lymphocytic panniculitis: An algorithmic approach to lymphocytes in subcutaneous tissue. J Clin Pathol 68: 954-962, 2015.

7. Thangapazham RL, Darling TN and Meyerle J: Alteration of skin properties with autologous dermal fibroblasts. Int J Mol Sci 15: 8407-8427, 2014.

8. Tobin DJ: Introduction to skin aging. J Tissue Viability, doi: 10.1016/j.jtv.2016.03.002, 2016 (Epub ahead of print).

9. Makrantonaki E and Zouboulis CC: Molecular mechanisms of skin aging: State of the art. Ann N Y Acad Sci 1119: 40-50, 2007.

10. Ha BG, Park MA, Lee CM and Kim YC: Antioxidant activity and anti-wrinkle effects of Aceriphyllum rossii leaf ethanol extract. Toxicol Res 31: 363-369, 2015.

11. Lee KO, Kim SN and Kim YC: Anti-wrinkle effects of water extracts of teas in hairless mouse. Toxicol Res 30: 283-289, 2014.

12. Braverman IM and Fonferko E; The elastic fiber network: Studies in cutaneous aging: I. The elastic fiber network. J Invest Dermatol 78: 434-443, 1982. 
13. Uitto J: Connective tissue biochemistry of the aging dermis Age-related alterations in collagen and elastin. Dermatol Clin 4: 433-446, 1986.

14. Varani J, Spearman D, Perone P, Fligiel SE, Datta SC, Wang ZQ, Shao Y, Kang S, Fisher GJ and Voorhees JJ: Inhibition of type I procollagen synthesis by damaged collagen in photoaged skin and by collagenase-degraded collagen in vitro. Am J Pathol 158: 931-942, 2001.

15. Philips N, Auler S, Hugo R and Gonzalez S: Beneficial regulation of matrix metalloproteinases for skin health. Enzyme Res 2011: 427285, 2011.

16. Fisher GJ, Datta SC, Talwar HS, Wang ZQ, Varani J, Kang S and Voorhees JJ: Molecular basis of sun-induced premature skin ageing and retinoid antagonism. Nature 379: 335-339, 1996.

17. Fisher GJ, Wang ZQ, Datta SC, Varani J, Kang S and Voorhees JJ: Pathophysiology of premature skin aging induced by ultraviolet light. N Engl J Med 337: 1419-1428, 1997.

18. Choi J, Kim TH, Choi TY and Lee MS: Ginseng for health care: A systematic review of randomized controlled trials in Korean literature. PLoS One 8: e59978, 2013.

19. Helms S: Cancer prevention and therapeutics: Panax ginseng. Altern Med Rev 9: 259-274, 2004.

20. Jang KJ, Choi SH, Yu GJ, Hong SH, Chung YH, Kim CH, Yoon M, Kim GY, Kim BW and Choi YH: Anti-inflammatory potential of total saponins derived from the roots of Panax ginseng in lipopolysaccharide-activated RAW 264.7 macrophages. Exp Ther Med 11: 1109-1115, 2016.

21. Kim HJ, Kim P and Shin CY: A comprehensive review of the therapeutic and pharmacological effects of ginseng and ginsenosides in central nervous system. J Ginseng Res 37: 8-29, 2013.

22. Kulaputana O, Thanakomsirichot S and Anomasiri W: Ginseng supplementation does not change lactate threshold and physical performances in physically active Thai men. J Med Assoc Thai 90: 1172-1179, 2007.

23. Finkel $\mathrm{T}$ and Holbrook NJ: Oxidants, oxidative stress and the biology of ageing. Nature 408: 239-247, 2000.

24. Jung SH, Woo MS, Kim SY, Kim WK, Hyun JW, Kim EJ, Kim DH and Kim HS: Ginseng saponin metabolite suppresses phorbol ester-induced matrix metalloproteinase- 9 expression through inhibition of activator protein-1 and mitogen-activated protein kinase signaling pathways in human astroglioma cells Int J Cancer 118: 490-497, 2006.

25. Attele AS, Wu JA and Yuan CS: Ginseng pharmacology: Multiple constituents and multiple actions. Biochem Pharmacol 58 1685-1693, 1999.

26. Christensen LP: Ginsenosides chemistry, biosynthesis, analysis, and potential health effects. Adv Food Nutr Res 55: 1-99, 2009.

27. Lee SM, Bae BS, Park HW, Ahn NG, Cho BG, Cho YL and Kwak YS: Characterization of Korean Red Ginseng (Panax ginseng Meyer): History, preparation method, and chemical composition. J Ginseng Res 39: 384-391, 2015.

28. Lee MR, Yun BS, In OH and Sung CK: Comparative study of korean white, red, and black ginseng extract on cholinesterase inhibitory activity and cholinergic function. J Ginseng Res 35: 421-428, 2011.

29. Bak MJ, Jeong WS and Kim KB: Detoxifying effect of fermented black ginseng on $\mathrm{H}_{2} \mathrm{O}_{2}$-induced oxidative stress in HepG2 cells. Int J Mol Med 34: 1516-1522, 2014.

30. Kang KS, Yamabe N, Kim HY, Okamoto T, Sei Y and Yokozawa T: Increase in the free radical scavenging activities of American ginseng by heat processing and its safety evaluation. J Ethnopharmacol 113: 225-232, 2007.

31. Hasegawa H, Sung JH and Huh JH: Ginseng intestinal bacterial metabolite IH901 as a new anti-metastatic agent. Arch Pharm Res 20: 539-544, 1997.

32. Yun TK: Experimental and epidemiological evidence on non-organ specific cancer preventive effect of Korean ginseng and identification of active compounds. Mutat Res 523-524: 63-74, 2003.

33. Gillis CN: Panax ginseng pharmacology: A nitric oxide link? Biochem Pharmacol 54: 1-8, 1997.

34. Hasegawa H, Sung JH, Matsumiya S and Uchiyama M: Main ginseng saponin metabolites formed by intestinal bacteria. Planta Med 62: 453-457, 1996.

35. Lee PS, Han JY, Song TW, Sung JH, Kwon OS, Song S and Chung YB: Physicochemical characteristics and bioavailability of a novel intestinal metabolite of ginseng saponin (IH901) complexed with beta-cyclodextrin. Int J Pharm 316: 29-36, 2006

36. Kim S, Kang BY, Cho SY, Sung DS, Chang HK, Yeom MH, Kim DH, Sim YC and Lee YS: Compound K induces expression of hyaluronan synthase 2 gene in transformed human keratinocytes and increases hyaluronan in hairless mouse skin. Biochem Biophys Res Commun 316: 348-355, 2004
37. Cho S, Won CH, Lee DH, Lee MJ, Lee S, So SH, Lee SK, Koo BS, Kim NM and Chung JH: Red ginseng root extract mixed with Torilus fructus and Corni fructus improves facial wrinkles and increases type I procollagen synthesis in human skin: A randomized, double-blind, placebo-controlled study. J Med Food 12: $1252-1259,2009$

38. Lee HS, Kim MR, Park Y, Park HJ, Chang UJ, Kim SY and Suh HJ: Fermenting red ginseng enhances its safety and efficacy as a novel skin care anti-aging ingredient: In vitro and animal study. J Med Food 15: 1015-1023, 2012.

39. Lee SA, Jo HK, Im BO, Kim S, Whang WK and Ko SK: Changes in the Contents of Prosapogenin in the Red Ginseng (Panax ginseng) Depending on Steaming Batches. J Ginseng Res 36: 102-106, 2012

40. Lee MR, Kim BC, Kim R, Oh HI, Kim HK, Choi KJ and Sung CK: Anti-obesity effects of black ginseng extract in high fat diet-fed mice. J Ginseng Res 37: 308-349, 2013.

41. Park HJ, Shim HS, Kim KS and Shim I: The protective effect of black ginseng against transient focal ischemia-induced neuronal damage in rats. Korean J Physiol Pharmacol 15: 333-338, 2011.

42. Sun BS, Gu LJ, Fang ZM, Wang CY, Wang Z, Lee MR, Li Z, Li JJ and Sung CK: Simultaneous quantification of 19 ginsenosides in black ginseng developed from Panax ginseng by HPLC-ELSD. J Pharm Biomed Anal 50: 15-22, 2009.

43. Ivarsson M, McWhirter A, Borg TK and Rubin K: Type I collagen synthesis in cultured human fibroblasts: Regulation by cell spreading, platelet-derived growth factor and interactions with collagen fibers. Matrix Biol 16: 409-425, 1998.

44. Fligiel SE, Varani J, Datta SC, Kang S, Fisher GJ and Voorhees JJ: Collagen degradation in aged/photodamaged skin in vivo and after exposure to matrix metalloproteinase-1 in vitro. J Invest Dermatol 120: 842-848, 2003.

45. Varani J, Dame MK, Rittie L, Fligiel SE, Kang S, Fisher GJ and Voorhees JJ: Decreased collagen production in chronologically aged skin: Roles of age-dependent alteration in fibroblast function and defective mechanical stimulation. Am J Pathol 168: 1861-1868, 2006.

46. Inomata S, Matsunaga Y, Amano S, Takada K, Kobayashi K, Tsunenaga M, Nishiyama T, Kohno Y and Fukuda M: Possible involvement of gelatinases in basement membrane damage and wrinkle formation in chronically ultraviolet $\mathrm{B}$-exposed hairless mouse. J Invest Dermatol 120: 128-134, 2003.

47. Visse R and Nagase H: Matrix metalloproteinases and tissue inhibitors of metalloproteinases: Structure, function, and biochemistry. Circ Res 92: 827-839, 2003.

48. Chakrabarti S and Patel KD: Matrix metalloproteinase-2 (MMP-2) and MMP-9 in pulmonary pathology. Exp Lung Res 31: 599-621, 2005.

49. Arpino V,Brock M and Gill SE: The role of TIMPs in regulation of extracellular matrix proteolysis. Matrix Biol 44-46: 247-254, 2015.

50. Kandalam V, Basu R, Abraham T, Wang X, Soloway PD, Jaworski DM, Oudit GY and Kassiri Z: TIMP2 deficiency accelerates adverse post-myocardial infarction remodeling because of enhanced MT1-MMP activity despite lack of MMP2 activation. Circ Res 106: 796-808, 2010.

51. Jezierska A and Motyl T: Matrix metalloproteinase-2 involvement in breast cancer progression: A mini-review. Med Sci Monit 15: RA32-RA40, 2009.

52. Varani J, Warner RL, Gharaee-Kermani M, Phan SH, Kang S, Chung JH, Wang ZQ, Datta SC, Fisher GJ and Voorhees JJ: Vitamin A antagonizes decreased cell growth and elevated collagen-degrading matrix metalloproteinases and stimulates collagen accumulation in naturally aged human skin. J Invest Dermatol 114: 480-486, 2000.

53. Lateef H, Stevens MJ and Varani J: All-trans-retinoic acid suppresses matrix metalloproteinase activity and increases collagen synthesis in diabetic human skin in organ culture. Am J Pathol 165: 167-174, 2004

54. Frankenberger M, Hauck RW, Frankenberger B, Häussinger K, Maier KL, Heyder J and Ziegler-Heitbrock HW: All trans-retinoic acid selectively down-regulates matrix metalloproteinase-9 (MMP-9) and up-regulates tissue inhibitor of metalloproteinase-1 (TIMP-1) in human bronchoalveolar lavage cells. Mol Med 7: 263-270, 2001.

55. Dutta A, Sen T, Banerji A, Das S and Chatterjee A: Studies on Multifunctional Effect of All-Trans Retinoic Acid (ATRA) on Matrix Metalloproteinase-2 (MMP-2) and Its Regulatory Molecules in Human Breast Cancer Cells (MCF-7). J Oncol 2009: 627840, 2009. 